\title{
An Educational Life and Legacy: Living and Leading Invitationally in Northern Ireland
}

\author{
Brendan Byrne Browne \\ Principal, Halton Catholic District School Board, ON, Canada
}

\begin{abstract}
Exploring the influence of a theory on practice reveals the applicability of educational leadership theory in contemporary schools. Invitational leadership suggests a theory of practice which encourages leaders to lead from a caring core, trust and respect others, be optimistic about the future and do so intentionally. While this approach to leadership may appear incongruent with the reality of education in sectarian Northern Ireland, this paper explores the educational life and invitational leadership of a veteran school principal in Belfast who committed to living and leading invitationally. Through stories, experiences, and reflections; invitational leadership theory is revealed as a theory of practice which has made an immense impact on a school community in East Belfast and should perhaps be more widely considered by scholars and educational leaders.
\end{abstract}

\section{Introduction}

Like many towns throughout Northern Ireland, Belfast is divided along social, political and historical lines. Sectarian enclaves throughout the city are clearly defined and proclaimed by murals, painted curbs and waving flags. Interaction between communities can be rare as long standing grudges, hatred, and mistrust persist. When Billy Tate became the principal of an elementary school in East Belfast he understood that the creation of an inviting school that included cross-community partnership might not be might embraced by all.

An inviting approach to educational leadership recognizes the impact school leaders have on the culture of the school, community, and student achievement. Education is more than what happens in schools. When seen as an activating ideal, the concept of education can be an imaginative act of hope focused on the possibility of developing human potential to live more educative lives [1]. While school leadership involves daily realities such as scraped knees, leaky roofs, challenging parents, discipline concerns, and staff development, it is also big picture thinking, strategic planning, and promoting educational living for both oneself and for others. While leadership theories may appear to provide theories for practice, Invitational Leadership suggests a theory of practice, grounded in the reality of contemporary schools. The tenants of invitational leadership including care, trust, respect, optimism and intentionality as revealed in the five Ps: places, people, programs, policies, and processes; continue to positively impact contemporary principals and school communities [2] but they could not possibly work in a politically and socially divided Belfast. Or could they?

Billy Tate embraced an inviting approach to school leadership as a principal in East Belfast and in doing so revealed the universal applicability of invitational theory. Conventional wisdom might suggest invitational leadership theory should not work in sectarian East Belfast, yet Billy intentionally pursued the creation of an inviting school despite outspoken opposition throughout the community. His thoughtful consideration of the 5 Ps of inviting leadership not only established a community committed to educational living inside the school and throughout the community, it also resulted in a school which was recognized internationally for cross-border partnerships and community relations. The school was lauded with a Marcel Rudloff Prix de la Tolerance Award in Strasbourg and a visit to the school from the sitting President of Ireland, Mary McAlesse, while Billy himself was made a Member of the British Empire by Queen Elizabeth II.

The turning point for Billy's approach to leadership came as he read Inviting School Success [15], Inviting Educational Leadership [14], Creating Inviting Schools [12] and attended a lecture lead by invitational theorist Dr. John Novak. He decided that he needed an approach to leadership which was grounded in practice. Billy committed to doing things on purpose for purposes that could be defended. For an approach to take hold in education it needs to resonate with an educator's deepest emotions and intuitions, provide a defensible intellectual position, and lead to creative and ethical practices [1]. Invitational leadership theory involves an investment in people and developing cooperative relationships for educational purposes. Everyone is 
always sending messages which are being received and interpreted by others. The inviting perspective aims to be a coherent theory of practice by focusing on the consistency and direction of the messages that are sent through people, places, policies, and programs, with the aim of making schools places that intentionally invite educational living for all [1].

How did a man with a Loyalist Protestant upbringing from Armagh come to embrace crossborder and community partnerships, promote the Irish language, culture and sport, and welcome the President of the Republic into his school on an official visit? While the story extends well beyond this paper, his commitment to invitational theory as a relevant, influential theory of practice reveals the interconnection of theory and practice and how the consideration of how ideas can influence contemporary schools.

\section{Literature Review}

The realities of school leadership present significant challenges for principals in all communities but those realities as they manifest in East Belfast can seem insurmountable. The work of Billy Tate reveals how the consideration of theory and intentional application can support school leaders and influence communities.

\subsection{Challenging Leadership}

The role of principal is fraught with stress, isolation, role anxiety, and culture shock as principals embrace not only instructional leadership, but concurrently managerial, administrative, financial, and supervisory responsibilities [7]. Regardless of the circumstances of promotion and political, social, or cultural influences, principals are expected to enter the profession adequately prepared to perform all roles and duties competently in order to support student learning and positively influence school culture and administration. The reality is that many principals are overwhelmed as they struggle with their new role identity [4]. Many principals confess to feeling unprepared for the level of expertise required for mediation, difficult parents, teacher supervision, site and facilities management, administrative tasks, and the time and toll taken on families in the role [17].

The completion of preparation courses and qualifications are required for school principals. These preparation programs are intended to equip school leaders academically and practically with the theory and skills required for the position. The general consensus from practicing principals is that these programs, while regarded as necessary, fail to adequately prepare emerging principals for the realities of the role [6]. Practitioners and scholars advocate for on-going mentorship to support transitioning principals with their socialization and competency [4].

The application of theory may not be at the forefront of many new principal's minds as they begin their tenure as academic leaders. In fact, a perception exists of a gap between theory and practice within education [10][18]. Educational scholars engage in research in order to influence practice and make a contribution to contemporary schools yet there is little tangible evidence to indicate that their work actually results in change for teachers in the classroom [10]. The language of the academy is cited as providing a barrier to the influence of theory on practice and a move away from academic language to that of conversation is a suggested example of reducing the distance between educators and scholars [5].

This disconnect continues to focus on the concept of relevance. Literature and theory are not being consumed and implemented because of the perception of the lack of application to the reality of daily life in a school. The concept of administrators as scholars, though an admirable pursuit, requires a "leap of faith to conclude that traditional academic frames of scholarship have much application to the world of practice” [11, p. 853]. Murphy [11] argues that the gap is perpetuated by the lack of practitioners teaching leadership preparation courses at universities and the resulting inapplicability of academic pursuits to the everyday role of a school leader

Perhaps ironically, as revealed above, research supports the fact that research is perceived as having little influence on practice. The reading preferences of scholars and practitioners vary significantly as scholars report preferring peer-reviewed journals while practitioners prefer non-peer reviewed magazines focused on practice and regulations [18]. Despite this perception, Billy immersed himself in theory by reflecting on practice, valuing experience, and refining for future practice as a school leader. Inviting schools do not happen by accident as it is intentionality that sets this philosophy apart [2]. The publication of articles such as this reveal the applicability of theory in a tangible way as Billy's leadership was significantly influenced by invitational leadership theory and the creation of an inviting school in East Belfast.

\subsection{Philosophical Foundations}

Inviting leadership is Dewey-ian in its approach as dealing with experiences is meant to make experiences better. Concepts must be applicable to action as reality itself is only a result of interaction. Dewey refers to the interaction between the organism and environment as transactional realism [3]. Without transaction, philosophy is reduced to mere 
theory. It is the process of inquiry that should shape our concept of being [6].

The domain of knowledge and action are not separate but are intimately connected as knowledge emerges from action. Experience is the key to knowledge as experience is the philosophy of action [6].

Educational inquiry is both the beginning and the end as it provides both the source of the problems while also providing the test of value [3]. The ultimate purpose of education is to make the actions of educators more intelligent as leaders develop practical wisdom [16]. Exercising practical wisdom involves the ability to perceive, to empathetically connect and utilize appropriate feelings, to deliberate, and to act accordingly [16]. Wisdom has to be practical because issues faced by leaders are grounded in everyday work rather than hypothetical dilemmas or intellectual exercises. Acting wisely demands that leaders are guided by appropriate aims or goals for an activity and that wisdom moves the general goals into practical action [16].

Our understanding of research and theory should not tell us what to do but instead provide options for the future. Research and practice must inform each other in a continuous way. An invitational approach to leadership reflects a practically wise approach to leadership as the leader leads from a caring core by intentionally trusting, respecting, and being optimistic about the future as experiences inform both decisions and practices in pursuit of morally defensible goals.

\subsection{Invitational Theory}

As a principal first in Armagh and then in East Belfast, Billy Tate sought knowledge that would inform his practice and influence his leadership. He was introduced to invitational theory at a professional development day for fellow principals by Dr. John Novak, author of inviting Educational Leadership [9] and Creating Inviting Schools [8]. Invitational leadership theory involves an investment in people and developing cooperative relationships for educational purposes. The inviting perspective aims to be a coherent theory of practice by focusing on the consistency and direction of the messages that are sent through people, places, policies, and programs, with the aim of making schools places that intentionally invite educational living for all [1]. Billy connected with the ideas rooted in care, trust, respect, optimism, and intentionality and recognized the connection to practice through the five Ps: places, people, policies, programs and processes. Billy read more about invitational leadership, connected with Dr. Novak via email, and committed to creating an inviting school in East Belfast despite the evidence that suggested it was not possible.
Based on the concept of "inviting" others to participate in the leadership of the school, invitational leaders foster a culture of open collegial collaboration accomplished through trust, respect, optimism, care, and intentionality and invite educational living not just for students, but for all members of the community - students, teachers, parents, and the wider community. The pursuit of educational living does not provide the specific details for developing a shared educational ideal. It is grounding and a returning point for extended conversations and should be seen as a work in progress. Ideals are not fully attainable ends but experiential, intellectual, and ethical means for living a more fulfilling life which the inviting leader lives. From the point of view of John Dewey [8], the best way to prepare to live educationally in the future is to work to live an educational life in the present.

If theory is a way of thinking and practice is that which is worth doing, a theory of practice is thinking about the value of action, being intentional and reflective before, during, and after [9]. Inviting leaders recognize the gifts and talents that others bring to the table and trust in their ability to contribute to the school. They invite others to work collaboratively with their heart, head, and hands [9].

Committing to living and leading invitationally is not about the implementation of a strategy but rather an embracement of a philosophy of being that encourages others to do the same. Leadership is an art and we have the responsibility for moral action that influences the lives of people [10]. An inviting leader must respect others, foster trust between people in the organization, care for the process of leading, be optimistic that better futures are possible, and do it all intentionally. The way in which this is manifest is revealed in the five "Ps": places, people, programs, policies, and processes.

While the tenants of trust, respect, optimism, care, and intentionality as reveals in the five "Ps" may seem like a wonderful theoretical idea on the page, what does it look like in practice? Can care, optimism, trust, respect and intentionality flourish in sectarian Belfast? Billy Tate committed to invitational leadership and invited others to contribute to the creation of an inviting school where history, experience, and logic suggested it was not possible. The results of Billy's leadership are staggering as he sought to not only transform a school but an entire community.

\section{Methods and Results}

Over the course of three years, Billy Tate shared the triumphs and struggles of leading invitationally and his journey from a young teacher from Stranmillis College to the principal in a border town in Armagh and in East Belfast. In Armagh the principal he replaced had been shot and community 
members were regularly targeted because of their choice of school. Checking the wheel wells of their cars each night was common practice for all staff members. He shared his frustration with the reality of violence and the day he went to a colleagues' home in the wake of her husband being shot. The desire to contribute to positive change in Northern Ireland encouraged Billy's pursuit of leadership opportunities and his exploration and contemplation of invitational leadership as a theory of practice capable of influencing that transformation.

In mentorship conversations via email and in an interview at his home in the North of Ireland, Billy shared his pride in a staff that welcomed the President of Ireland and staff and students whose embrace of the creation of an inviting school culminated in Billy being made a Member of the British Empire. He also revealed the reality of a school community struggling to shake off a sectarian past but reminded of the bitter history by paramilitary parents uninterested in inviting anyone other than those within their estate. It is through these interviews and mentorship conversations that Billy Tate reveals invitational leadership in practice through the five "Ps".

\subsection{People}

Conversations with Billy electronically and personally as well as a visit to his school and interviews with staff reveal his appreciation for the importance of people and relationships to a healthy school community. He possessed the rare gift of being able to develop positive relationships with everyone regardless of their political or religious persuasion and modeled this for his staff and community. He took the perspective that it is easy for someone to hate those they do not know personally. He lived that mantra when he hired a Catholic teacher without the knowledge or consent of the Board of Governors. His intention was to embrace her in the school and have the community know her and appreciate her for the person and teacher she is rather than the primary school she attended or the politics of her community. He conveniently forgot to file the appropriate paperwork and by doing so put himself on a limb by staking his reputation on the hiring of a teacher the board would never have agreed to because of her religion and the school she attended as a child.

They way in which Billy worked toward the elimination of unnecessary hierarchy within the school by respecting the contribution of all contributed to the success of his inviting school. When the school was recognized with the Marcel Rudloff Prix de la Tolérance Award in Strasburgh, he made the decision to bring representatives from the entire staff including teachers, educational assistants, and support staff. He could have easily travelled to Strasburg alone as the head of the school and received it on behalf of everyone but instead insisted on equal representation of all contributors to the school for the special occasion. Similarly, when staff was invited to Dublin to visit the President of Ireland's home, he piled everyone onto a bus and brought them all down for the reception. When President McAleese expressed an interest in visiting the school, Billy encouraged staff to lead the organization of both the big picture and the details of the event, knowing that their contribution was paramount to the success of the occasion. Their embracement of this responsibility took advantage of the many talents and gifts of staff, while encouraging an investment in the success of such a controversial event for the East Belfast community.

Billy further revealed his people-centric approach to invitational leadership by committing to knowing the names of all students in the school. Before students arrived in September, he took the time to go over the class lists and connect the names of students to their photos so that he could address them by name immediately and establish an inviting environment for all students from the beginning of September.

An inviting school recognizes and celebrates the contributions of all to the creation of an inviting learning environment. Walking together in moments of difficulty and times of triumph are equally important.

\subsection{Places}

Billy recognized the importance of place to the creation of an inviting school. He refused to remain idyll when paramilitary groups hung flags around the community and the school proclaiming "For God and Ulster" with the red hand of Ulster. The flags were indications of loyalist Protestant politics which clearly delineated territories around the city. To Billy, these flags represented the ultimate intentionally disinviting stance. Though the men that put up flags were tough, at times violent men, he used all available contacts and resources to prevent them from flying not only immediately around the school but around the entire community. Billy regarded the flags as intentional defiance to the creation of an inviting school by a minority of community members bent on the continuing to isolate themselves socially and politically. Taking a stand against these men required bravery and savvy in order to live by the principles he professed to himself, the staff, and community. They were put up individuals who were not strangers to violence and to carrying through with threats. Billy understood that these flags sent a strong signal to all that only some people were welcome in the community and the school. In order to live and lead educationally, he stood up to those who raised the flags and stood by 
his commitment to create a school that was inviting to all.

The school was further made into an inviting one by moving from a place where parents were required to remain outside of the gates when he first arrived to a community hub in which parents could come into the school for programs, to connect with one another, and to foster community. His use of the school for community building events such as quiz nights opened it up to the outside and encouraged cooperation and transparency. Classrooms became places of welcome for parents to engage in the learning of students in partnership with the teachers by prioritizing a welcoming environment.

\subsection{Programs}

The embracement of the Dissolving Borders project at the school invited the students to put aside their preconceptions and enter into relationship with students they would not normally be in contact with. The program also invited students from Catholic communities in Northern Ireland and the Republic into the school virtually and physically with mutual visits. Participating in cross border relations programs invited the reconsideration of accepted societal norms and historical divisions by encouraging students to connect personally rather than politically. Further participation in community and family swaps whereby Catholic families would host and put up students and that hospitality was reciprocated invited deeper understanding and movement beyond tolerance and into relationship with one another.

Billy introduced athletic programs to East Belfast such as hurling; a sport traditionally associated with the republican community in the north and Irish dancing at the school. Students participated in and learned about these Irish traditions as sport and culture and a way to invite cross-community dialogue and understanding and an embracement of Irish heritage. Billy understood that invitational leadership and an inviting school could not be fully realized within an intentionally segregated and isolated community. Though fiercely and publicly opposed by many within the community, Billy persevered in the face of intimidation and threats, courageously optimistic that better futures were possible through inviting programs. The day after Billy passed away from cancer, an honour guard of hurling sticks was erected at Croke Park in Dublin in his honour before a game between school boys from Northern Ireland and the Republic.

\subsection{Policies}

Billy established a morning coffee policy that encouraged parents to venture beyond the exterior gates and into the school each morning to develop community and fellowship and establish relationships. The simple act of inviting parents into the school each day for coffee changed the perception of the relationship between the parents and academic communities and began to forge partnerships. Inviting parents into classes which were previously out of bounds developed mutual trust between parents and teachers. By doing so Billy discovered talents and a willingness to share within the community which further contributed to the school.

His policy of including all members of staff in all decision making recognized the gifts and talents of each individual and the potential contribution that each can make to the community. Whether planning for meetings, the President's visit, or being invited to sit on a committee with the Taoiseach, Billy made it policy to have all voices heard by insisting on seats at the table for all stakeholders. Furthermore, his policy of including all members of the staff in recognition awards and ceremonies invited equality and mutual respect amongst staff members.

\subsection{Processes}

The hiring of a Catholic teacher at the school reveals Billy's understanding of the importance of process and how to utilize it creatively. He used the hiring process to his advantage to provide the opportunity for a teacher to become part of the community who would not normally have if the processes were followed to the letter of the law rather than the spirit of the law. He understood how things worked and then did what he thought was the right thing to do in congruence with his vision of the creation of an inviting school.

When the paramilitary groups began protesting the visit of the President of Ireland by threatening to protest and put up Ulster flags around the community, instead of entering into conflict with them, Billy invited them into the school to participate in the process of planning and encourage them to become part of the visit rather than in opposition to it, much to the horror of the President's security detail. The result was the removal of flags as they attended peacefully knowing their concerns were heard as Billy's process for hearing their voices resulted in inviting them in instead of shutting them out. The protest groups were seeking conflict and prepared for a fight in order to make a statement. Billy prepared to collaborate and listen. Disarmed by a respectful, inclusive response, the paramilitary group acquiesced and accommodated.

\subsection{Leading Personally and Professionally}

An inviting approach to leadership does not make a distinction between leading personally and professionally as one cannot be one way at school 
and another at home. Invitational leadership is about leading, managing, and mentoring for educational lives. Leadership is about creating the conditions to invite, encourage, and sustain educational living. Managing is about providing the structures necessary to support those within the organization to live educational lives. Mentoring is about inviting more people to participate in and sustain an educational vision [1]. Billy lived educationally by not separating his personal life from his professional life. He understood what was required of him to lead and committed himself to lead by example by consistently taking courses and inviting others to take advantage of professional development opportunities and modeling life-long learning and curiosity. When offered a pay raise, he took the money and quietly re-invested it into the professional development of some of his younger staff unbeknownst to them. As he reached the point in his life where money no longer mattered, he lived a life of service to his staff and sacrificed so others could have the opportunity to learn and grow as educators which would ultimately make an impact on the students and community at the school.

He hosted dinner parties at his home at which he invited prominent members of vehemently oppositional organizations to sit down together for dinner as he opened the doors of his home and revealed an individual committed to inviting peace in the community by working for it in the school and his own home. Members of both major communities along with police officers, clergymen, and politicians all sat together and shared a meal together as he lived his assertion that hate could not persist amongst people when forced to confront one another in civilized ways. Invitational leaders recognize the congruence between personal and professional and Billy lived this within his home one dinner at a time.

\subsection{Critical Reflections}

An inviting approach to leadership requires a commitment to intentionally living from a caring core, respecting and trusting others, being optimistic about a better future. In order to successfully lead educational change, leaders need to connect with what staff are already doing well, see how it can be extended or added to, and collectively articulate where they should be going and why [1]. People constantly do good things in schools. It is important for an educational leader to recognize, highlight, and build on these in order to call forth and sustain educational growth [1]. As simple as it sounds, living it requires courage, persistence, and as Billy often said, a degree of calculated "daftness" to get through difficult situations. Leading in a community used to sectarian divisions and generations of mistrust of the other could have been straightforward if he had simply perpetuated the societal norms.
Instead, Billy committed to creating an inviting school in a community in which murals, painted curbs, and sectarian flags clearly shouted "keep out" to a large portion of the population. It had been that way for generations and he could have easily maintained the existing norms. Instead, he spoke out, stood up, lead, managed, and mentored invitationally and in doing so provided an example of educational living.

Staff was not on board immediately and some perhaps remained reluctant throughout. A vocal portion of the community sought to maintain the status quo. His interpersonal skills and courage saw new initiatives through despite opposition allowing the time for new ideas, programs, policies, and processes to gain traction in the community.

Invitational theory provided more than a framework for Billy; it offered a way to live an educational life that was congruent with his goals for the school and community and encouraged reflection, contemplation and refinement throughout. Does living and leading invitationally require a "superman" principal willing to stand up in the face of danger both real and imagined?

While Billy's approach to leadership changed the culture of his school so significantly that it was recognized with a Marcel Rudloff Prix de la Tolérance Award in Strasburgh, a visit from the President of Ireland, and being personally made a Member of the British Empire, questions remain about the sustainability of an inviting school once the inviting leader is no longer at the helm. A strong leader develops leadership in others and shared responsibility. Using Hargreaves [9] work on sustainable leadership, Novak and Dibiase [13] apply the ten principles of sustainable leadership to an inviting school. Hargreaves [9] suggests sustainable leadership involves ten principles: substance, enduring, diffusive, socially just, resourceful, promotes diversity and builds capacity, activistic, vigilant, respects the past, and patient. Through the lens of sustainable leadership, Novak and DiBiase [13] suggest that invitational leadership should involve an in-depth understanding and commitment by all in the organization, should not be reliant on a charismatic leader, and responsibility should be collectively diffused throughout the school rather than through a select few. In an inviting school, leadership is shared by the principal, teachers, parents, students and community members. There is a commitment to and emphasis on social justice in the wider world, promote diversity of ideas, build capacity amongst within the school, and find new and creative ways to do so. Remaining vigilant, respecting that past to build better futures, and patience matched with pragmatic hope based on persistence, resourcefulness, and courage works together to sustain inviting schools [13]. 
Inviting leadership is meant to be more than the leader him or herself, it should change the culture of the organization entirely. Whether the school can maintain the great gains in cross community relations and intentionally inviting practice under Billy's leadership will only be revealed over time. What Billy Tate's leadership does reveal is the way in which an inviting leader can live and lead in the most challenging of circumstances.

While one might rightfully expect care to be at the core of all school leadership; it could be argued that trust, respect and optimism can be challenging in a politically and socially segregated community. Reflection on Billy Tate's approach to the creation of an inviting school reveal not only the applicability of an inviting theory of practice, but also that it can make enormously positive changes in the most demanding school communities. It is through this reflective critical analysis of theory in practice that the implications for school leaders are revealed while concurrently influencing invitational leadership as a constantly evolving theory of practice.

The stories themselves are informative, engaging and inspiring for school leaders and scholars alike as they reveal the actual implications of inviting leadership theory in a school through the five "Ps": what it looks like in action and the impact on teachers, students, parents, the community, and the leadership of the school.

\section{Conclusion and Recommendations}

Invitational leadership theory respects experiences rather than suggesting prescriptive approaches. An inviting approach is intended to provide a rationale for shared power, difficult choices, and ethical action so that dealing with political issues can be an educative experience which contributes to living an educational life. Leadership is about going below the surface and facing life's ambiguities, confusions, and challenges with a creative and caring flair [1]. There is a selfcorrecting element as Billy Tate embraced Michael Fullan's "ready, fire, aim" approach to educational practice. Billy committed to living an idea and invited others to do the same, resulting in the creation of an inviting school where no one expected an inviting school to be. Billy Tate's leadership in East Belfast reveals the impact and applicability of invitational leadership in contemporary schools. If Billy could live and lead invitationally in East Belfast, it should be considered a theory of practice worth exploring and a wide variety of contexts as an example of theoretical influence on educational leadership.

These reflections on Billy Tate's leadership reveal the real impact and applicability of the theory of invitational leadership in contemporary schools and the influence an inviting leader can make on a school community regardless of the social, historical or political circumstances. The leadership of Billy Tate provides evidence of the intentional bridging of the knowledge gap and the evaluation of considerate educational leadership grounded concurrently in theory and practice.

\section{References}

[1] Armstrong, D., Browne, B., \& Novak, J. (in progress). Leading for educational lives: Inviting imaginative acts of hope in an interconnected world. Rotterdam: Sense Publishers Inc.

[2] Asbill, K. (2006). The most inviting place in town. In J.M. Novak, W. Rocca, \& A.M. DiBiase (Eds.), Creating inviting schools. (pp. 9-36). San Francisco: Caddo Gap.

[3] Biesta, G. J. J. and Burbles, N. C. (2003) Pragmatism and educational research. Toronto: Rowan \& Littlefield Publishers, Inc.

[4] Browne-Ferrigno, T. \& Muth, R. (2006). Leadership mentoring and situated learning: Catalysts for principalship readiness and lifelong mentoring. Mentoring and Tutoring. 14(3), pp. 275-295.

[5] Carson, T.R. (1986). Closing the gap between research and practice: Conversation as a mode of doing research. Phenomenology and Pedagogy, 4(2), pp. 73-85.

[6] Daresh, J. \& Male, T. (2000). Crossing the border into leadership: Experiences of newly appointed british headteachers and american principals. Educational Management \& Administration. 28(1), pp. 89-101.

[7] Davis, S. H. (2007). Bridging the gap between research and practice: What's good, what's bad, and how can one be sure? Phi Delta Kappan. 88(8), pp. 568-578.

[8] Dewey, John. (1938). Experience and education. New York: Simon and Shuster.

[9] Hargreaves, A. (2005). Sustainable leadership. In B. Davies (Ed.) The essentials of school leadership. London, UK: Paul Chapman.

[10] Holland, P.E. (2004). Principals as supervisors: A balancing act. NASSP Bulletin. 88(639), pp.3-14.

[11] Murphy, J. (2007). Questioning the Core of University-Based Programs for Preparing School Leaders. Phi Delta Kappan. 88(8), 582-585. 
[12] Novak, J.M., Rocca, W. \& DiBiase, A.M. (Ed.). (2006). Creating inviting schools. San Francisco: Caddo Gap.

[13] Novak, J.M and DiBiase, A.M. (2006). Sustaining inviting schools. In J. Novak, W. Rocca, and A.M. DiBiase (Eds.) Creating inviting schools. San Francisco: Caddo Gap Press.

[14] Novak, J.M. (2002). Inviting educational leadership. Toronto: Pearson Education.

[15] Purkey, W.W. \& Novak, J. (1996). Inviting school success: A self-concept approach to teaching, learning,and democratic practice, $3^{\text {rd }}$ edition. Florence, Kentucky: Wadsworth Publishing Inc.

[16] Schwartz, B. (2010). Practical wisdom: The right way to do the right thing. New York: Riverhead Books.

[17] Walker, K., Anderson, K, Sackney, J. \& Wolfe, J. (2003). Unexpected learning by neophyte principals: factors related to success of first year principals in schools. Managing Global Transitions. 1(2), pp. 195-213.

[18] Zirkel, P.A. (2007). The professoriate, the practitioners, and 'their' periodicals. Phi Delta Kappan. 88(8), 586-589. 